\title{
O PATRIMÔNIO CULTURAL E AS PRISÕES: APAGAMENTOS E SILENCIAMENTOS ${ }^{1}$
}

\section{Cultural heritage and prisons: erasures and silences}

\author{
Viviane Trindade Borges*
}

\begin{abstract}
RESUMO
O presente artigo analisa a patrimonialização de memórias, acervos e edifícios ligados a história das prisões brasileiras. Tratarei da ausência de tombamentos em nível Federal e da destruição de edificações carcerárias que datam do século $\mathrm{XX}$, período em que o Brasil viveu um verdadeiro boom na construção de presídios e penitenciárias. Paralelo ao descaso em relação aos edifícios, é possível observar inciativas que visam a preservação do patrimônio carcerário em sua dupla dimensão: material e imaterial. Nesta perspectiva, serão analisados alguns casos emblemáticos, como o Presídio de Tiradentes, em São Paulo e a Penitenciária de Florianópolis, em Santa Catarina.
\end{abstract}

Palavras chave: patrimônio carcerário, prisões, lugares de memória, preservação, Brasil.

\begin{abstract}
This article analyzes the preservation of memories, collections and buildings related to the history of Brazilian prisons. I will deal with the absence of policies for the preservation of these assets at the Federal level and the destruction of prison buildings dating back to the twentieth century, a period in which Brazil experienced a real boom in the construction of prisons and penitentiaries. Parallel to the neglect of buildings, it is possible to observe initiatives aimed at preserving the prison heritage in its double dimension: material and immaterial. In this perspective, we will analyze some emblematic cases, such as the Tiradentes Prison in São Paulo and the Florianópolis Penitentiary in Santa Catarina.
\end{abstract}

Keywords: prison heritage, prisons, places of memory, preservation, Brazil.

1 Esta pesquisa teve apoio do Conselho Nacional de Desenvolvimento Científico e Tecnológico - CNPq, Edital Universal 14/2014.

* Doutora em História Universidade Federal do Rio Grande do Sul. Professora do Programa de Pós-Graduação em História da Universidade do Estado de Santa Catarina. 
Em 2014 o Museu Penitenciário Paulista passou a funcionar em nova sede, localizada nas dependências do antigo Complexo do Carandiru, na cidade de São Paulo, incorporando também um novo acervo: "o acervo mostra um pouco da criatividade dos presos que participavam de oficinas nas penitenciárias. As pinturas impressionam pelos detalhes e pelo capricho. Várias são da década de 1930 e precisaram ser restauradas. Tem também micro-ondas improvisados com lâmpada e papel alumínio, móveis cheios de detalhes, e até uma motocicleta em miniatura. Tudo construído atrás das grades, desde 1920. [...] As criações proibidas dos presos nas celas também estão no meio das 21 mil peças do acervo do museu. No acervo há armas construídas com diversos tipos de materiais. Os improvisados aparelhos de tatuagens também. Tem até uma engenhoca para fazer cachaça com restos de comida. $\mathrm{O}$ visitante pode conhecer ainda as celas escuras, extintas na década de 1970, que serviam como uma espécie de punição pra alguns presos. $(28 / 07 / 2104)^{2}$.

O trecho citado divulga um espaço museológico e um vasto acervo ligado a história do sistema prisional brasileiro, referente a uma tragédia prisional, o massacre do Carandiru ${ }^{3}$. Pensar o espaço prisional enquanto patrimônio cultural é uma novidade ainda pouco discutida no Brasil. A ausência de políticas públicas voltadas especificamente a preservação do patrimônio carcerário é quebrada por iniciativas de alguns grupos sociais interessados na preservação destas memórias marginais, e instigada por políticas de memória que nos últimos anos possibilitaram a patrimonialização de lugares relacionados ao período militar.

Tratarei aqui de patrimônios marginais, bens estigmatizados por aquilo que representam, espacos de difícil interpretação e aceitação no meio urbano, devido ao medo e repulsa que instigam. Como pensar o valor histórico e patrimonial de memórias, acervos e edifícios ligados a história das prisões brasileiras? O presente artigo

2 http://g1.globo.com/sao-paulo/noticia/2014/07/museu-penitenciario-paulista-comecafuncionar-nesta-terca-feira.html. Acesso em 22/004/2015.

3 A respeito dos usos da memória ligados ao massacre do Carandiru e suas intersecções com a história pública: BORGES, Viviane. Carandiru: os usos da memória de um massacre. Revista Tempo e Argumento, vol. 3. 2016. 
analisa a ausência de tombamentos em nível Federal e a destruição de edificações carcerárias que datam do século XX, período em que o Brasil viveu um verdadeiro boom na construção de presídios e penitenciárias. Paralelo ao descaso em relação aos edifícios é possível observar inciativas que visam a preservação da memória carcerária em sua dupla dimensão: material e imaterial.

\section{Patrimônio Carcerário no Brasil: uma ausência}

A expressão "patrimônio carcerário" ainda é pouco conhecida entre os pesquisadores brasileiros. Ela ganhou força recentemente na França, através de iniciativas como a realização do Colloque L'architecture carcérale, des mots et des murs" organizado em 2010 pela Ecole Nationale d'Administration Pénitentiaire, e de publicações como a obra intitulada "Prisons : Patrimoine de France" (2013), que traz 2500 fotos de prisões francesas, destacando as marcas deixadas pelos presos como desenhos, pinturas e escritas em paredes e edificações. A abertura para visitação da Prison de La Santé, em Paris, durante as Jornadas do Patrimônio francês de 2014, marcou definitivamente a emergência do tema dentro das discussões ligadas ao patrimônio cultural na França.

No Brasil os debates a respeito da importância patrimonial dos espaços prisionais ainda são incipientes. Nesse sentido, cabe citar o pioneirismo da criação do Ecomuseu da Ilha Grande, que buscou "preservar a memória de práticas de violência e de arbitrariedade ética e moral, que são ou estereotipadas ou totalmente ignoradas pela sociedade ${ }^{4,}$. Myriam Sepúlveda dos Santos salienta o embate trabalho entre a vontade de preservar e um movimento de reiterado apagamento da memória da instituição e da sua história. ${ }^{5}$ Essa

4 BORGES, Viviane. Carandiru: os usos da memória de um massacre. Revista Tempo e Argumento, vol. 3. 2016, p. 15.

5 SANTOS, Myrian Sepúlveda dos. Os conflitos entre natureza e cultura na implementação do Ecomuseu Ilha Grande. Hist. cienc. saude-Manguinhos [online], v.12, suppl., p.381-382, 2005. Disponível em: < http://dx.doi.org/10.1590/S0104-59702005000400020>. Acesso: 
vontade de apagamento perpassa o debate a respeito do patrimônio carcerário, apagamento de edificações, memórias e acervos. No que tange aos edifícios, a preocupação com o futuro de edificações já desativadas em virtude da necessidade de adaptação as exigências impostas pela legislação ${ }^{6}$ e dos efeitos da forte pressão imobiliária, que acaba expulsando tais locais dos centros urbanos, corroboram a necessidade urgente de se refletir sobre o tema.

A categoria patrimônio carcerário envolve não apenas a dimensão edificada desses bens, mas sob uma perspectiva mais ampla e disseminada, englobando aspectos imateriais e materias. Envolve a preservação da memória dos sujeitos envolvidos no cotidiano prisional: «os sentenciados, seus familíares e os funcionários das instituições », problematizando a dimensão imaterial da experiência prisional, suas rotinas e suas práticas cotidianas. «Envolve ainda a preservação dos acervos prisionais, documentais e/ou objetos tridimensionais: prontuários de presos, livros de registro, fotografias, cadeiras de identificação, uniformes, móveis e utensílios, incluindo aqui as « criações proíbidas dos presos », vestígios por estes deixados durante o período de reclusão ». A preservação destes acervos por parte das instituições nem sempre atende à condições minímas de conservação, o que implica na perda de documentos fundamentais para pensar a história das prisões no Brasil e suas especificidades nos diferentes estados brasileiros ${ }^{7}$.

$\mathrm{Na}$ "Lista de bens tombados e Processos em andamento" do órgão federal responsável pela preservação do patrimônio cultural brasileiro, o Instituto do Patrimônio Histórico e Artístico Nacional (IPHAN), entre 1938 e 2015, encontram-se apenas 27 bens relacionados ao patrimônio carcerário. A listagem mostra que a preservação dos locais destinados a punição no Brasil perpassa edificações do Período Colonial e parte do Imperial, referindo-se principalmente as antigas Casas de Câmara e Cadeia.

02/07/2015, 2009. ISSN 0104-5970, p. 394.

6 Conforme o Projeto de Lei 3.506-A, de 2004, é proibida a «construção de penitenciárias, presídios ou similares dentro do perímetro urbano dos Municípios Brasileiros».

7 BORGES, Viviane. Carandiru: os usos da memória de um massacre. Revista Tempo e Argumento, vol. 3. 2016, p. 16. 
No Brasil, a criação do SPHAN (Serviço do Patrimônio Histórico e Artístico Nacional), atual IPHAN, instituiu a prática do tombamento como principal mecanismo legal de proteção dos bens culturais, criado através do Decreto-Lei número 25, de 1937. O tombamento é um dispositivo legal que pode ser usado pelo poder público federal, estadual e municipal para preservar a memória nacional, detentora de valores universais ou compartilhados pela comunidade, no qual se reconhece o valor cultural de determinado bem e determina a preservação de seus elementos, garantindo sua preservação física. Constitui uma ação do poder executivo através de abertura de processo que pode ser implementado por qualquer cidadão (pessoa física ou jurídica), insituição pública ou privada. Tombar não é o único instrumento legal de preservação dos bens culturais brasileiros, cabendo também aos Estados e Municípios impletar leis e mecanismos de preservação. Os planos diretores das cidades, por exemplo, estabelecem formas de preservação do seu patrimônio através do planejamento urbano, ficando livres para criar leis específicas para a preservação deste. ${ }^{8}$

Por um período que se estende da criação do IPHAN em 1937 até a década de 1970, o entendimento a respeito do que era patrimônio cultural no Brasil esteve restrito a um tipo muito particular de bem, priorizando os chamados bens de pedra e cal, edificações ligadas principalmente ao período colonial e de origem lusa. A visão contemporânea e mais abrangente, de patrimônio como bens selecionados de nossa cultura, ligados às identidade de comunidades e grupos, institui valor patrimonial também ao que foge do monumental e do material ${ }^{9}$. Essa ampliação do campo patrimonial, iniciada no Brasil a partir dos anos de 1970, mas efetivamente consolidada com a Constituição de 1988, permite pensar o patrimônio de uma maneira mais ampla e incluir lugares de memória ${ }^{10}$ vinculados a diversas

8 http://portal.iphan.gov.br. Acessado em: 29/05/2015.

9 FONSECA, Maria Ceclia Londres. O patrimônio em processo. Rio de Janiero: Editora da UFRJ, 2009.

10 Os caminhos trilhados pela recepção do conceito de lugar de memoria no Brasil resultaram em apropriações diversas e por vezes conflitantes. A noção ganhou novos usos, os quais por vezes se afastam da problematização crítica a respeito dos usos do passado e das batalhas de memórias, incitadas por Nora (2012), caminhando para uma banalização elogiosa sobre o passado recordado. Tal noção é aqui utilizada para problematizar os usos do passado que permeiam a 
esferas do social. Tal perspectiva coaduna com a compreensão contemporânea de patrimônio em nível internacional, que através de iniciativas como a inclusão do campo de concentração e extermínio de Auschwitz-Birkenau na Lista do Patrimônio Mundial da UNESCO, propõe que o "patrimônio não é apenas um relicário de testemunhos estéticos da atividade humana", mas uma noção que ressona no social através do dever de memória em relação a vítimas de crimes de Estado ${ }^{11}$. Frente a estes novos sentidos, podemos pensar questões ligadas a patrimônios marginais, vinculados a instituições e/ou grupos sociais estigmatizados, como o patrimônio carcerário.

Voltando a lista dos bens tombados pelo IPHAN, podemos observar que os bens edificados ligados ao patrimônio carcerário foram preservados em função da singularidade de arquitetura. Cito o exemplo da Casa de Câmara e Cadeia do Município do Brejo da Madre de Deus, em Pernambuco, a qual consta na referida lista. A edificação é apontada como um exemplar da arquitetura "neoclássica brasileira", harmoniosamente inserida junto aos "casarões típicos" do século XIX. Soma-se a isso o fato ter sido projetada por Louis Legér Vauthier, engenheiro francês reconhecido por suas importantes obras na Pernambuco do século XIX, como o Teatro Santa Isabel (1940) e o Mercado São Jose (1871). A importância atribuída a preservação de exemplares arquitetônicos do século XIX se sobrepõe ao valor histórico e social do espaço enquanto local de punição. As Casas de Câmara e Cadeia eram casarões de dois pisos que cumpriam a função de Cadeia Pública e Câmara Municipal. Com a promulgação código penal de 1890, o espaço destinado ao cumprimento da pena ganha novas formas: instalações em formato de espinha de peixe, pavilhonares, com características panópticas, moldando a arquitetura das penitenciárias contemporâneas brasileiras.

É paradigmático não encontrarmos na referida lista de bens tombados pelo IPHAN nenhuma referência à instituições penais do

preservação de edificações, acervos e memórias vinculadas ao patrimônio carcerário. NORA, Pierre. Entre a memoria e a historia: a problematica dos lugares. In: Projeto Historia. No 10. Sao Paulo, PUC-SP, dez. 1993.

11 MENEGUELLO, Cristina. Patrimônio sombrios, memorias dificies. In: FLORES, Maria Bernardete Ramos \& PETERLE, Patricia [orgs.]. Historia e Arte. Herenca, Memoria, Patrimonio. Sao Paulo: Rafael Copetti Editor, 2014, p. 54. 
século XX. Se pensarmos nas políticas públicas do período republicado, tanto a Republica Velha $(1889-1930)^{12}$ quanto a Era Vargas $(1930-1945)^{13}$ foram responsáveis pela construção de dezenas de importantes edificações, muitas em estilo moderno e ainda em funcionamento, como hospitais gerais, psiquiátricos, sanatórios para tuberculose, leprosários e penitenciárias, espaços que mediaram as inciativas governamentais de controle e proteção da sociedade. ${ }^{14}$ Essas edificações nem sempre se inserem no consenso construído a respeito do que deve ser preservado: são lugares de difícil inserção e aceitação na teia urbana, deslocados ou abandonados, que provocam repulsa, medo e/ou recordações dolorosas. O patrimônio carcerário é aqui entendido como patrimônio marginal, locais destinados aos desviantes, estigmatizados por representarem aquilo que a sociedade produziu e que deseja isolar e esquecer. A preservação de memórias marginais estimula a criação de espaços de reflexão que instigam mudanças, que provocam a solidariedade em relação ao outro, que exigem humanização.

Durante a Era Vargas e na Ditadura Militar (1964-1985) ${ }^{15}$, algumas Penitenciárias, presídios e delegacias abrigaram também os presos políticos indiciados, foi este o caso do Presídio de Tiradentes e do Carandiru, em São Paulo e da Penitenciária de Florianópolis, em Santa Catarina, analisadas no presente artigo. Por Tiradentes passaram nomes como Monteiro Lobato ${ }^{16}$, escritor preso durante o Estado Novo (1937-1945) ${ }^{17}$ e a ex-presidenta Dilma Rousseff, presa

12 Período que se estende da proclamação da República, em 1889, ate a Revolução de 1930.

13 Refere-se ao período em que Getúlio Vargas governou o Brasil.

14 A respeito da patrimonialização de leprosários e hospitais psiquiátricos no Brasil ver: BORGES, Viviane e SERRES, Juliane Conceição Primon. Leprosários e Hospitais Psiquiátricos: lugares de história, lugares de memória. In: GONZALEZ, Ana María Sosa et al. Patrimônio Cultural: Brasil e Uruguai os processos de patrimonialização e suas experiências. Pelotas: Ed. da Universidade Federal de Pelotas, 2013. - 243p.

15 Período em que os militares conduziram o país, marcado por repressão, censura, tortura, mortes, perseguições políticas e suspensão dos direitos constitucionais. A abertura dos arquivos relacionados a Ditadura Militar brasileira vem possibilitando o aprofundamento de pesquisas relacionados ao tema o qual vem sendo amplamente estudado.

16 José Bento Renato Monteiro Lobato (1882-1948), nascido em Taubaté (SP), foi um importante escritor brasileiro, um dos primeiros autores de literatura infantil da América Latina, sua obra mais conhecida e "Sitio do Picapau Amarelo".

17 O Estado Novo, instituído por Getúlio Vargas, é caracterizado pela centralização do poder, autoritarismo, nacionalismo e anticomunismo, marcado por medidas como por exemplo, o 
durante o período militar, permanecendo três anos na chamada "Torre das donzelas", edificação em estilo colonial localizada dentro do complexo. ${ }^{18}$

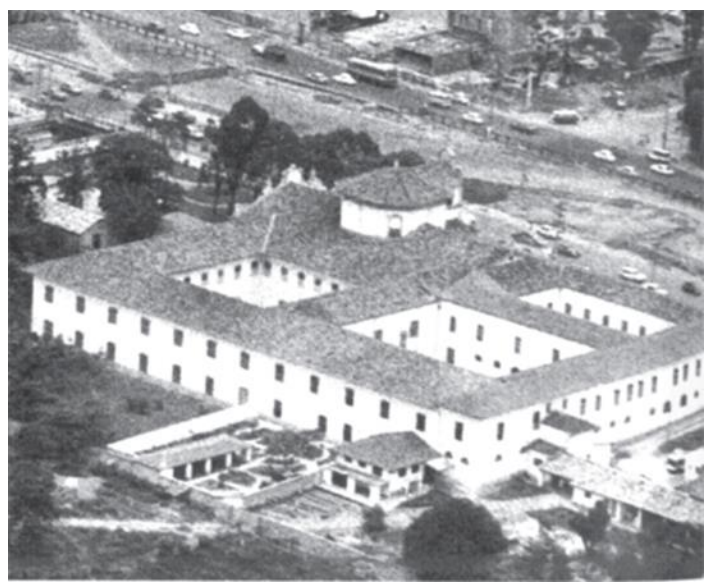

Prisão Tiradentes. A Torre das Donzelas é o edifício redondo no centro ${ }^{19}$.

O Presídio de Tiradentes foi demolido ao final de 1972 em função das obras do metrô, dele restando apenas o Arco de Pedra do portal de entrada, construído na década de 1930. Em 1985 o Arco foi tombado pelo CONDEPHAAT (Conselho de Defesa do Patrimônio Histórico Arqueológico, Artístico e Turístico de São Paulo), considerado patrimônio cultural da cidade. $\mathrm{O}$ pedido de tombamento foi feito em 1984 pelo Sindicato dos Jornalistas Profissionais no Estado de São Paulo, com o apoio de diversas organizações da sociedade civil e de direitos humanos, solicitando "sua transformação em Monumento Público". ${ }^{20}$

fechamento do Congresso Nacional e a extinção dos partidos políticos, ocasionando uma série de prisões arbitrarias daqueles que contestavam o governo. Acessado em: 01/08/2015.

http://www.istoe.com.br/reportagens/83253_A+TORRE+DAS+DONZELAS.

19 Photo: http://www.istoe.com.br/reportagens/83253_A+TORRE+DAS+DONZELAS. Acessado em: 20/08/2015.

20http://www.memorialdaresistenciasp.org.br/memorial/upload/memorial/bancodedado s/130740251278039152_192_PRESIDIO_TIRADENTES.pdf. Acessado em: 22/05/2015. 

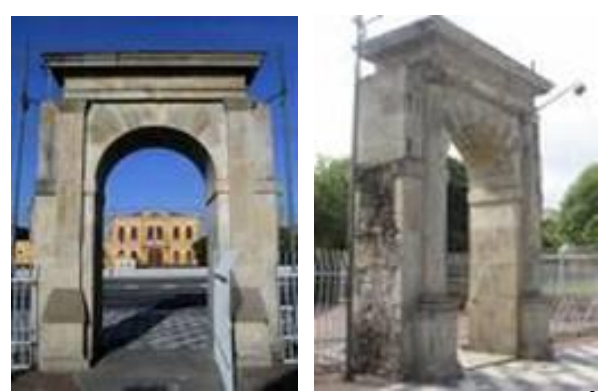

Arco de Pedra, restos do Presídio de Tiradentes ${ }^{21}$.

O monumento é aquilo que faz lembrar, evocando o passado em um movimento dever de memória. Choay propõe uma distinção entre monumento e monumento histórico que coteja elementos importantes para etendermos a ressignificação atribuída ao Arco de Pedra. Monumento seria algo universal, comum as diferentes sociedades, concebido intencionalmente com o objetivo de "lembrar, para a memória viva, orgânica e afetiva dos seus membros, pessoas, acontecimentos, crenças, ritos ou regras sociais constitutivos de sua identidade". O monumento histórico não possui intencionalidade, não nasce como monumento, trata-se de algo escolhido deliberadamente por determinada sociedade em razão de seu valor histórico e/ou por seu valor estético e por ela investido de valor patrimonial. "Todo objeto do passado pode ser convertido em testemunho histórico sem ter tido na sua origem um destino memorial" ${ }^{22}$. A autora aponta a substituição do termo "monumento histórico" pelo termo "patrimônio", expressão utilizada durante a revolução francesa, ligada a ideia de transmissão, ressurgida na década de 1960. No Brasil, com a Constituição de 1988, o termo Patrimônio Histórico e Artístico, foi substituído pela expressão Patrimônio Cultural, revitalizando e ampliando o conceito ${ }^{23}$, referindo-se a bens "de natureza material e

21 Photo: http://www.sap.sp.gov.br/common/museu/museu.php. Accès en: 23/08/2015.

22 CHOAY, Francoise. O patrimônio em questão. Antologia para um combate. Belo Horizonte, Fino Traco, 2011, p. 12-22.

$23 \mathrm{http}: / /$ portal.iphan.gov.br/pagina/detalhes/218. Acessado em: 11/05/2015. 
imaterial, tomados individualmente ou em conjunto, portadores de referência à identidade, à ação, à memória dos diferentes grupos formadores da sociedade brasileira".

O Arco de Pedra, vestígio de uma instituição carcerária inaugurada em 1852, cuja história perpassou as funções de casa de correção, depósito de escravos e cárcere político em dois momentos distintos da história do país, tornou-se monumento histórico, foi instituído como patrimônio cultural. Sua preservação faz ressurgir a importância histórica e social do prédio demolido, não deixando apagar suas memórias ligadas a episódios sombrios da história brasileira. Investido de valor patrimonial, o monumento torna-se "símbolo da luta contra o arbítrio e a violência.",24

Na América Latina, casos como Museo de la Memoria, na Argentina, criado junto ao espaço da Escola Superior de Mecânica da Armada (ESMA), onde funcionou (entre 1976 e 1983) Centro Clandestino de Detenção; e do Memorial da Resistência de São Paulo, no Brasil, no local onde funcionava (entre 1940 e 1983), o Departamento Estadual de Ordem Politica e Social de São Paulo (DEOPS/SP), lugares marcados por torturas, desaparecimentos e mortes, desvelam a emergência de políticas de memória que intencionam patrimonializar passados traumáticos, como forma de apaziguar o presente, servindo como exemplos para que isso não mais se repita.

A criação da Rede Global de Sítios de Consciência corrobora o forte interesse contemporâneo em resignificar locais relacionados às memórias da dor em lugares de memória, procurando garantir espaços seguros para preservá-las. A Rede é composta por "pessoas, Sítios e iniciativas que ativam o poder dos lugares de memória para engajar o público na conexão do passado e do presente, a fim de prever e moldar um futuro mais justo e humano." Com mais de 150 membros espalhados por 47 países, a Rede volta-se à temas específicos e questões de caráter global, como igualdade de gênero, imigração,

24 Parecer de Lúcio Felix Frederico Kowarick, conselheiro do CONDEHAAT em 01 de abril de 1985. Folha 014 do processo de Tombamento no 23345/85, pg. 16, disponível em: < http://www.arquicultura.fau.usp.br/index.php/encontre-o-bem- tombado/uso-original/administracaopublica/portal-de-pedra-do-antigo-presidio-tiradentes>, acessado em 19/05/2014. 
impunidade, xenofobia e exclusão, ditadura e repressão, tortura e prisão. $^{25}$

A criação destes espaços e sua preservação contribuem para a expansão com conceito de patrimônio cultural, trazem à tona questões ligadas a preservação de lugares de sofrimento, colocando na ordem do dia o debate a respeito da preservação de prisões, espaços de punição, interrogatório e tortura, transformando-os em locais de conscientização. Esse "trabalho de preservação proporciona a patrimonializacão de locais marcados pelo sofrimento, os quais são convertidos em monumentos em toda a polissemia da palavra, como locais de lembrança, advertência, como testemunhos dos tempos passados, como símbolo, como antídoto contra o esquecimento" 26 . Lançam luz sobre edificações esquecidas, muitas já demolidas ou remodeladas, apagadas, varridas do cenário urbano, cujas histórias ainda reverberam no presente.

No Brasil, a configuração de espaços de memória, como museus e memoriais dentro de instituições prisionais são comumente iniciativas locais, difíceis de serem mapeadas, não havendo estudos que sistematizem a existência destes lugares nos diferentes estados brasileiros. A esse respeito cito um último e recente exemplo, relacionado a Penitenciária de Florianópolis, no estado de Santa Catatina.

Em 2010, quando a instituição completou 80 anos, foi criado o Memorial da Penitenciária, um espaco composto por objetos e fotografias que tratam da história do espaço prisional. A Peniteciária foi inaugurada em 1930, em consonância com o já mencionada política nacional de constituição de uma rede de institiuições de controle social. Em 2012 o Projeto Arquivos Marginais, do Laboratório de Patrimônio Cultural da Universidade do Estado de Santa Catarina (LabPac/UDESC), organizou uma nova exposição junto ao $\mathrm{Memorial}^{27}$ e iniciou a higienização do acervo da institução,

25 http://www.sitesofconscience.org. Acessado em 12/06/2015.

26 BORGES, Viviane e SERRES, Juliane Conceição Primon. Leprosários ao sul do brasil: de locais de sofrimento a lugares de memória. Acervo, rio de janeiro, v. 28, n. 2, p. 252-263, jul./dez. 2015, p. 256.

27 A este respeito ver: Borges, Viviane Trindade . «O tempo abre as portas a quem sabe esperar»: usos do passado e embates do presente no percurso da exposição realizada na Penitenciária de Florianópolis (SC). Esboços (UFSC), v. 21, p. 236-250, 2014. 
composto por fotografias, objetos e prontuários de detentos. Em 2013 os Prontuários e as fotografias ${ }^{28}$, entre as décadas de 1930 e 1970, foram cedidas ao Instituto de Documentação e Investigação em Ciências Humanas (IDCH) da UDESC, para serem salvaguardadas. Tal iniciativa contribui para a preservação da memória carcerária, preservando um acervo documental importante para pensar a história das prisões no Brasil e suas especificidades. ${ }^{29}$
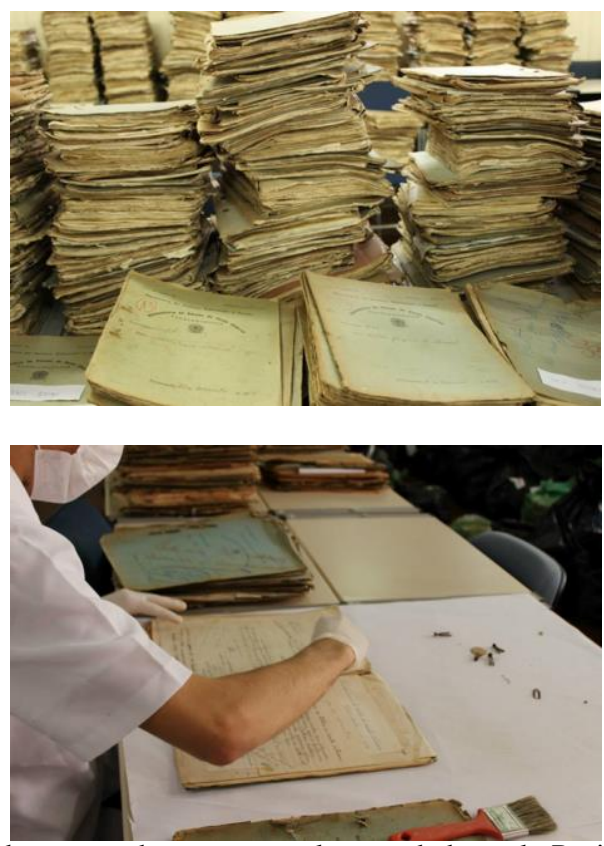

Prontuários de presos, documentos salvaguardados pelo Projeto Arquivos Marginais. Foto: Fernanda Biava.

Além do trabalho de preservação do acervo, as edificações Penitenciária foram investidas de valor patrimonial pelo município. $\mathrm{O}$

$28 \mathrm{O}$ acervo conta 4.209 prontuários e 80 fotografias.

29 Sobre o Projeto Arquivos Margianis ver: BORGES, Viviane. Arquivos Marginais: outras fontes, outros acervos. Revista Eletrônica Ventilando Acervos, Florianópolis, v. 4, n. 1, p. 1 54, dez. 2016. 
Complexo encontra-se em uma área urbana de alto valor imobiliário e desde a década de 1980 é possível acompanhar através da imprensa as inúmeras críticas em relação aos problemas em sua estrutura, além de fugas e rebeliões que colocam em risco os moradores vizinhos ao complexo $^{30}$. A presença desse patrimônio marginal em frente a um dos cartões postais da cidade, a Avenida Beira Mar Norte, tornou-se um problema constante para as autoridades locais e uma demanda social de ampla e controversa discussão. A transferência gera embates quer pela lentidão com que as decisões são tomadas, quer pela resistência dos municípios selecionados em abrigar o novo espaço, quer pelas controvérsias em relação ao destino da área.

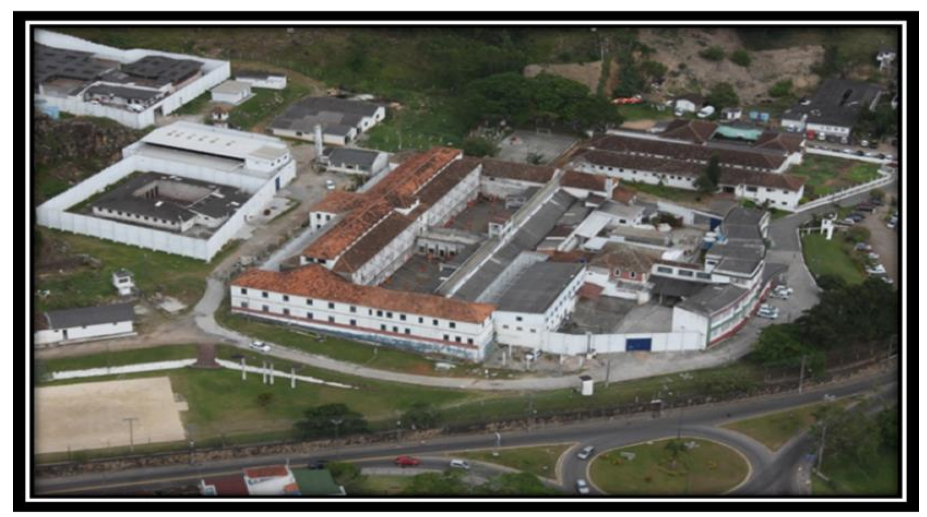

Penitenciária de Florianópolis. Foto: Memorial da Penitenciária.

30 Só em 2011 fugiram do Complexo 174 presos. http://ndonline.com.br/florianopolis/noticias/12653-mudanca-da-penitenciaria-de-florianopolis-ecerta-falta-o-local.html. Acessado em: 20/05/2015. 


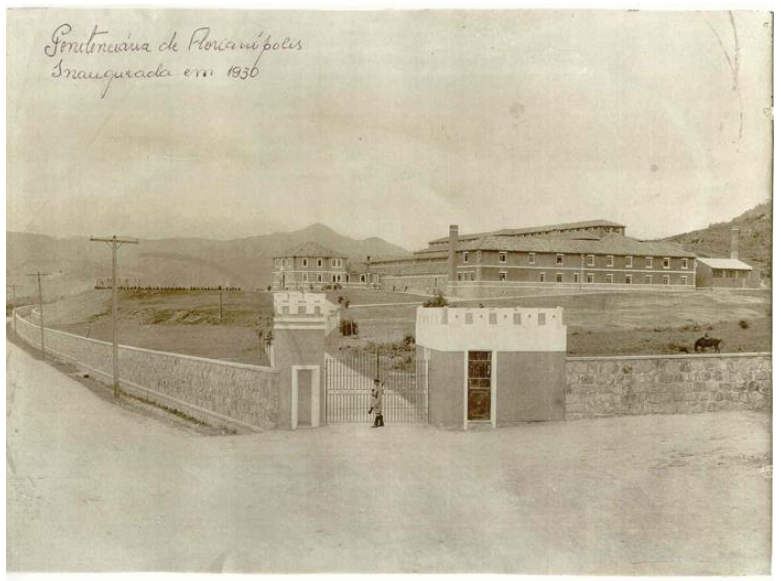

Penitenciária de Florianópolis, década de 1930. Foto: Arquivo Público do Estado de Santa Catarina (APSC)

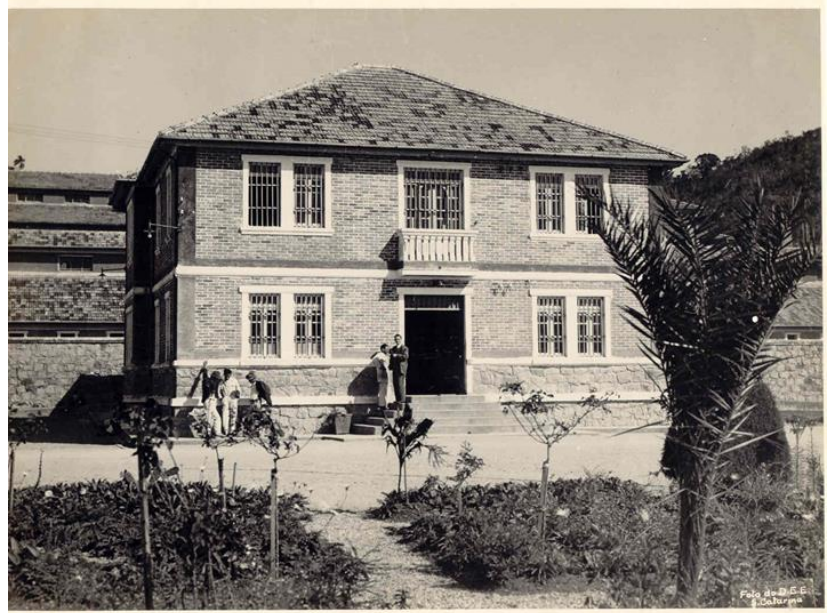

Casa Velha, 'decada de 1930. Atualmente essa edificação está encoberta pelas novas edificações construídas ao longo dos anos no interior do Complexo Penitenciário. Foto : Fundo Penita/ IDCH. 
Existem reinvindicações ligadas a necessidade de preservação patrimonial do Complexo, ressaltando "o valor histórico do imóvel, inclusive por sua adequação com o passado da região". ${ }^{31}$ Tal discussão tornou possível que em 2007 o Complexo se tornasse Área de Preservação Cultural (APC1), através do Decreto Lei no 375 de 2010, uma iniciativa do Município de Florianópolis através do Serviço do Patrimônio Histórico, Artístico e Natural (SEPHAN), órgão vinculado ao Instituto de Planejamento Urbano de Florianópolis (IPUF). Esse mecanismo de proteção esta ligado ao Plano Diretor de Florianópolis e prevê áreas de preservação integral ou apenas parte de áreas externas. No caso da Penitenciária foram protegidos em sua integridade o Bloco Penitenciário e o Bloco administrativo, ambos da década de 1930, o Bloco Administrativo da década de 1960, a Lavanderia, caramanchão e o muro frontal ${ }^{32}$.

Conforme o Superintendente do IPHAN/SC: "Acerca das possibilidades de reutilização da área, sugerimos que deva ser considerada como imprescindível a memória do uso atual dos edifícios". Tal indicação marca um novo entendimento em relação ao patrimônio carcerário, valorizado em função de seu uso ordinário, enquanto espaço prisional. A Penitenciária é entendida como parte da tessitura da cidade, identificada como marco referencial históricocultural, "por tratar-se de elemento que apresenta grande visibilidade, dominância visual e se sobressai na paisagem urbana do Município" ${ }^{33}$.

Outros elementos são elencados no documento para justificar a importância de se preservar o conjunto, como a singularidade de sua arquitetura, sua importância histórica no processo de urbanização e seu potencial de reinserção na dinâmica da cidade. A Penitenciária é apontada como um exemplar único de «momentos distintos e representativos dos períodos arquitetônicos, justapondo exemplares historicistas da arquitetura oficial e modernista. Ambas expressões

31 A Notícia, Palhoça descarta a Penitenciária, 10/01/2007, s/p.

32 A respeito da preservação do complexo: MISSIO, Ligia. Um recordar positivo: A criação e a reulamentação de Preservação Cultural do Complexo Penitenciário da Agronômica. Trabalho de Conclusão de Curso. Bacharelado em Museologia, Universidade Federal de Santa Catarina, 2014.

33 Santa Catarina. Brasil. IPUF. APC-1, Complexo Penitenciário da Agronômica, 2007. 
artísticas são estilisticamente únicas no território municipal». A iniciativa do municípo em preservar uma institução pertencente ao século XX por sua importância «histórico-cultural», enunciando como fundamental a preservação da memória do uso atual dos edifícios, evidencia uma nova percepção a respeito do patrimônio cultural, permitindo que memórias marginais também sejam valoradas como representativas da sociedade que as criou, instigando a sua resinserção na dinâmica da cidade através de uma reconfiguração de sentidos, compatibilizando «a memória construída, readequada para o uso atual, junto com construções contemporâneas, harmonizadas no contexto» ${ }^{34}$.

A preocupação em preservar o Complexo e pensar o aprofundamento sobre seu potencial de uso e a revitalização de suas edificações é também uma preocupação de determinados grupos. Em 2009, uma Moção feita pelos Professores de Arquitetura da Universidade Federal de Santa Catarina (UFSC) propõe a realização de estudos a respeito sobre o potencial de uso, integrando o espaço ao Centro Integrado de Cultura (CIC), local que abriga o Museu de Arte de Santa Catarina (MASC), Museu de Imagem e Som (MIS), teatro e cinemas. Conforme os professores: "os quase quarenta hectares da Penitenciária poderiam ser mais bem aproveitados se estendêssemos a vocação cultural e cívica desempenhada pelo Centro Integrado de Cultura (CIC) para algo como um Complexo de Lazer e Cultura, junto com outros equipamentos e atividades" 35 .

A preservação do Complexo mostra um avanço significativo frente a inexistência de políticas de requalificação urbana preocupadas com a preservação do patrimônio carcerário, contudo, a antiga Vila Operária construída ao lado do Complexo e hoje tomada como parte deste, não foi apontada no processo como parte do conjunto a ser preservado. A Vila foi inaugurada concomitantemente a Penitenciária em 1930, a fim de servir de moradia aos funcionários, visto que neste momento o local era tido como distante do centro da cidade. Com a ampliação da Penitenciária em 1935, o aumento do

34 Santa Catarina. Brasil. IPUF. APC-1, Complexo Penitenciário da Agronômica, 2007 , p. 2-3.

35 Santa Catarina. Brasil. IPUF. Moção dos Professores de Arquitetura Universidade Federal de Santa Catarina, Ano de 2009. 
número de funcionários, os quais em muitos casos acabavam trazendo suas famílias para a região, acabou impulsionando a ocupação do Bairro Agronômica. A exemplo das outras instituições aqui citadas, algumas das casas da Vila Operária foram utilizadas como prisão para presos políticos durante o Regime Militar, fato este silenciado no processo de patrimonialização do Complexo.

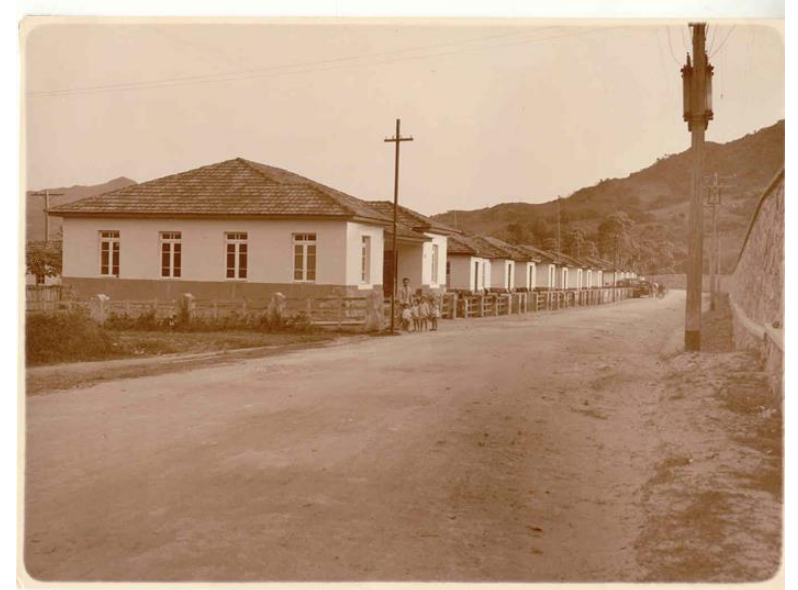

Vila Operária, década de 1940. Foto: Fundo Penita/IDCH

A Vila Operária e a Penitenciária estão interligadas, a salvaguarda de parte do Complexo de forma isolada dificulta a compreensão da história da instituição e do próprio bairro. Resquício do patrimônio industrial, a Vila não é sequer mencionada no documento que regulamenta a preservação do Complexo pelo município. Apesar de ter adquirido maior visibilidade nos últimos anos, o patrimônio industrial é ainda tido como um patrimônio difícil, distante do consenso ordinário. ${ }^{36}$ De forma semelhante ao patrimônio carcerário, os espaços do passado industrial são marginalizados, tidos 
como empecilhos para o crescimento das cidades. Não garantir a preservação legal da Vila Operária indica a possibilidade de destruí-la quando ocorrer a transferência do Complexo. Contudo, ainda que resguardada por um instrumento de preservação, também o processo de proteção das edificações da Penitenciária corre o risco de ser revogado. Tratando das negociações para a construção de um novo complexo em outro local, distante do centro urbano, conforme aponta a legislação atual, vem sendo aventada a venda do terreno para a iniciativa privada, pensando na construção de prédios residenciais na área, uma das mais valorizadas de Florianópolis, bem como a construção de um hospital público. ${ }^{37}$ De forma semelhante ao que ocorre em relação ao patrimônio industrial, a preservação deste tipo de bem dificilmente ocorrerá através de políticas públicas ligadas a requalificação e preservação patrimonial, mas sim por meio de grupos específicos interessados na temática carcerária.

O patrimônio cultural define-se pela atribuição de valores instituídos nos embates travados pela sociedade, uma teia tecida por diferentes agentes políticos sociais ligados a determinados momentos e a determinadas preocupações. Não é algo dado, mas algo construído, lapidado, selecionado, que envolve o desejo de memória de determinada sociedade, que institui o que considera importante transmitir através do tempo a outras gerações. Pensar o processo de preservação do patrimônio carcerário remete a preocupações do presente que envolvem a sociedade em geral, especialistas de diferentes áreas e órgãos de preservação em um trabalho de atribuição e renovação de sentidos.

Conforme relatório do Levantamento Nacional de Informações Penitenciárias (Infopen), referente a dezembro de 2014, a população carcerária brasileira chegou a 622.202 pessoas. De acordo com o documento o Brasil possui a quarta maior população carcerária do mundo, ficando atrás apenas dos Estados Unidos (2.217.000), China (1.657.812) e Rússia (644.237) ${ }^{38}$. Atribuir valor patrimonial a espaços que abrigam uma realidade aterradora, pensá-

37 http://floripamanha.org/2011/03/comunidade-discute-futuro-do-terreno-dapenitenciaria/. Acessado em: 31/05/2015.

38 http://www.justica.gov.br/noticias/mj-divulgara-novo-relatorio-do-infopen-nestaterca-feira/relatorio-depen-versao-web.pdf. Acessado em 10/05/2017. 
los com base em valores históricos, culturais, memoriais, não é um exercício fácil. Como discutir a importância destas edificações dentro dos espaços das cidades? Como dar sentido patrimonial a estes espaços estigmatizados? São questões a serem pensadas.

RECEBIDO EM: 01/03/2017 APROVADO EM: 01/06/2017 